\title{
Nanoparticle film deposition using a simple and fast centrifuge sedimentation method
}

\author{
Andrew R. Markelonis • Joanna S. Wang • \\ Bruno Ullrich • Chien M. Wai • Gail J. Brown
}

Received: 27 May 2014/ Accepted: 3 July 2014/Published online: 25 July 2014

(C) The Author(s) 2014. This article is published with open access at Springerlink.com

\begin{abstract}
Colloidal nanoparticles (NPs) can be deposited uniformly on flat or rough and uneven substrate surfaces employing a standard centrifuge and common solvents. This method is suitable for depositing different types of nanoparticles on a variety of substrates including glass, silicon wafer, aluminum foil, copper sheet, polymer film, plastic, and paper, etc. The thickness of the films can be controlled by the amount of the colloidal nanoparticle solution used in the preparation. The method offers a fast and simple procedure compared to other currently known nanoparticle deposition techniques for studying the optical properties of nanoparticle films.
\end{abstract}

Keywords Centrifuge $\cdot$ Films · Simple and fast . Nanoparticles · Deposition

\section{Introduction}

Semiconductor quantum dots (QDs) are attracting much attention recently due to their size-tunable properties and their wide range of potential applications such as lightemitting diodes (Colvin et al. 1994; Tessler et al. 2002), biological labeling (Bruchez et al. 1998; Michalet et al. 2005), sensors (Zhang et al. 2005), and solar cells (Huynh et al. 2002). For example, lead sulfide (PbS) QDs absorb

A. R. Markelonis - C. M. Wai

Department of Chemistry, University of Idaho, Renfrew Hall, Moscow, ID 83844, USA

\section{J. S. Wang $(\bowtie) \cdot$ B. Ullrich $\cdot$ G. J. Brown}

Materials and Manufacturing Directorate, Air Force Research Laboratory, 3005 Hobson Way, Wright-Patterson Air Force Base, OH 45433, USA

e-mail: jswang@uidaho.edu and emit light in the near-infrared (NIR) region, which makes them potentially important for telecommunication (Bakueva et al. 2004) and biotechnology applications (Medintz et al. 2005). Methods to deposit nanoparticles (NPs) on a variety of platforms are a key part of the technology development. Current procedures of depositing nanoparticles on solid surfaces include chemical vapor deposition (CVD) (Okada 2007), physical vapor deposition (PVD) (Kong et al. 2001), sputtering (Brodsky et al. 1977), lithography (Chou et al. 1997), spin coating (Chang et al. 2004), pulsed-laser deposition (PLD) (Aziz 2008), and supercritical fluid $\mathrm{CO}_{2}\left(\mathrm{sc}-\mathrm{CO}_{2}\right)$ deposition (Smetana et al. 2008; Wang et al. 2010). Most nanoparticle deposition techniques require specific equipment and a high level of technical expertise. For example, vapor deposition techniques require high-temperature and vacuum chambers. Spin coating requires highly concentrated nanoparticle solutions and a viscous polymer matrix. A vacuum chamber is required in the sputtering coating process. Layer-by-layer (LBL) deposition uses alternating layers of charged particles and a charged substrate (Decher et al. 1998). An in-depth and comprehensive knowledge of chemical processes is required for completing the LBL process. A high-power pulsed-laser beam, in pulsed-laser deposition, is focused inside a vacuum chamber to strike a target of the material that is to be vaporized and deposited as a thin film on a substrate. This process requires an ultra-high vacuum or presence of a background gas (Aziz 2008). The supercritical $\mathrm{CO}_{2}$ deposition method enables filling nanostructures of substrates with nanoparticles (Smetana et al. 2008; Wang et al. 2010; Ye et al. 2003) but involves operations at high pressure with specialized equipment and knowledge.

South et al. (South et al. 2009) fabricated microgels (water-soluble polymer cross-linked into a contiguous 
network)-based films using centrifuge deposition method. Ahmadi et al. (2013) used a stable suspension containing carbon nanotubes and polymethylmethacrylate (PMMA) (PMMA/carbon weight ratio $=0.05: 1)$ in cyclohexane solution to centrifuge and to form a smooth high-density carbon layer on the surface of graphite sample. Centrifuge deposition method has been used and reported previously for making a thin film. However, little has been explored in using centrifuge deposition for nanoparticle film formation. In this study, a facile and swift nanoparticle deposition method is described which utilizes only a standard centrifuge instrument and common solvents for the fabrication of nanoparticle films. This centrifuge deposition method $(\mathrm{CDM})$ is a very simple and efficient process that can be applied to a wide variety of substrates and different nanoparticles. It allows good coverage and thickness control of the nanoparticle films and layer-by-layer deposition of different nanoparticles in a very simple manner. This method also shows that the deposition can take place on flexible or rough surfaces, not limited to flat surfaces, such as flexible plastic, aluminum foil, copper sheet, etc. Gold $(\mathrm{Au})$ and lead sulfide $(\mathrm{PbS})$ NPs were arbitrarily selected for this study. Optical properties of Au and PbS NP films formed by this method are presented to demonstrate potential applications of the technique in the nanomaterials field.

\section{Experimental section}

Materials and substrates

Different substrates were chosen for the deposition of $\mathrm{Au}$ and PbS NPs, which included rigid, flexible, flat, rough, conductive, and insulating materials. The sizes of substrates usually were tailored to $5 \times 5 \mathrm{~mm}^{2}$. The materials used in this study include a plastic sheet [polyethylene terephthalate (PET)], aluminum foil, copper sheet, copper grid, flexible black or white plastic [6 $\mu \mathrm{m}$, high-density polyethylene (HDPE)], glass slide, paper, and silicon. Figure 1 shows some representative substrates used in this study with and without PbS NP coating. Transmission electron microscope (TEM) images were obtained from TEM $\mathrm{Cu}$ grids which were prepared with these substrates under the same experimental conditions and deposited with $\mathrm{Au}$, or PbS NPs. Scanning electron microscope (SEM) images of the $\mathrm{Au}$ and $\mathrm{PbS}$ NPs deposited on these substrates were also obtained. However, in this study, our emphasis is focused on the exploration of CDM method using Au and $\mathrm{PbS}$ NPs.

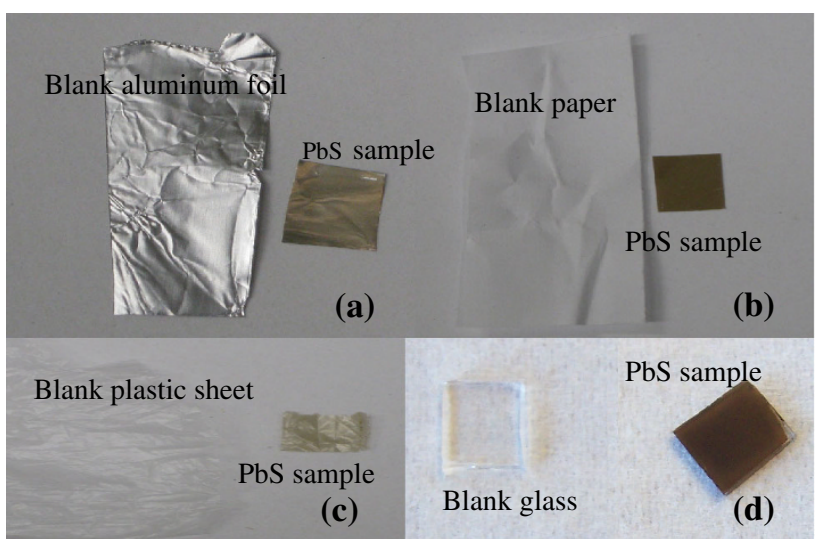

Fig. $1 \mathrm{PbS}$ NPs deposited by the centrifuge method on different substrates. Left: blank substrates and right: PbS NPs deposited on $\mathbf{a}$ aluminum foil, $\mathbf{b}$ paper, $\mathbf{c}$ plastic sheet, and $\mathbf{d}$ glass

\section{Preparation of $\mathrm{Au}$ and $\mathrm{PbS}$ nanoparticles}

Au nanoparticles

Hydrogen tetrachloroaurate(III) trihydrate (99.99\%), $\mathrm{NaCNBH}_{3}$ (95\%), hexanes, toluene, and sodium bis(2ethylhexyl)sulfosuccinate (AOT, $98 \%$ ) were purchased from Aldrich and used as received.

Gold NPs were prepared by the reduction of gold ions suspended in AOT water-in-hexane microemulsions. Separate metal ion and reducing agent solutions were prepared by dissolving $0.0178 \mathrm{~g}$ of AOT in $2 \mathrm{~mL}$ of hexane and adding an aqueous solution of $7.2 \mu \mathrm{L}$ (water/surfactant ratio, $W=10$ ) of either the $0.4 \mathrm{M} \mathrm{Au}^{3+}$ gold ion or the $1.2 \mathrm{M} \mathrm{NaCNBH} \mathrm{N}_{3}$ reducing agent. The $W$ value was manipulated by the amount of aqueous solution added. These micellar solutions were stirred for $1 \mathrm{~h}$ before reduction to equilibrate the reagents to the reaction temperature. The reaction was carried out at the ambient temperature. The microemulsion containing the reducing agent was added dropwise over a time span of $60 \mathrm{~s}$ to the gold ion-containing microemulsion under vigorous stirring. Dodecanethiol $(70 \mu \mathrm{L})$ was added to the reaction immediately after all of the reducing agents had been added to the solution. This solution was then allowed to stir at the reaction temperature for another hour. After this time, the gold particles were precipitated by adding a mixture of $6 \mathrm{~mL}$ of ethanol and $4 \mathrm{~mL}$ of methanol, followed by centrifugation. The supernatant was discarded, and the remaining particles were washed two more times with $5 \mathrm{~mL}$ of ethanol to remove AOT, spectator ions, and excess dodecanethiol. Multiple sets of the particle samples were combined, re-suspended in $1 \mathrm{~mL}$ of toluene or hexane, and the final concentration was approximately $0.005 \mathrm{M}$. All procedures were conducted on the bench-top without the 
need for inert environments. Detailed procedure can be found in the literature (Smetana et al. 2007).

$\mathrm{PbS}$ nanoparticles

Hexane, toluene, octadecene (ODE), bis(trimethylsilyl)sulfide (TMS), oleic acid (OA), ethanol, and methanol were purchased from Aldrich and used as received.

Oleic acid-capped $\mathrm{PbS}$ nanoparticles were prepared, in principle, in a similar manner to Hines and Scholes (2003) but with some modifications. $0.25 \mathrm{~mL}\left(0.8 \times 10^{-3} \mathrm{~mol}\right)$ oleic acid, $0.09 \mathrm{~g} \mathrm{PbO}\left(0.4 \times 10^{-3} \mathrm{~mol}\right)$, and $42 \mu \mathrm{L}$ of TMS $\left(0.2 \times 10^{-3} \mathrm{~mol}\right)$ were used at a molar ratio of 4:2:1.

$\mathrm{PbO}(0.09 \mathrm{~g})$, ODE (3.9 mL), and OA $(0.25 \mathrm{~mL})$ were added in a 3-neck reaction flask, in vigorous stirring, under a flow of continuous argon (Ar) gas at $150{ }^{\circ} \mathrm{C}$ for $1 \mathrm{~h}$. After $1 \mathrm{~h}$, TMS $(42 \mu \mathrm{L})$ dissolved in $2 \mathrm{~mL}$ of ODE was quickly injected at $150{ }^{\circ} \mathrm{C}$ into the reaction flask, while the magnetic stirrer was vigorously working and Ar gas was continuously passed through. The solution color changed from colorless to dark brown immediately. The heating source was removed and the temperature reduced to $100-120^{\circ} \mathrm{C}$. The temperature of the system was kept at this temperature range and the stirring continued under Ar gas for another hour.

The sample was washed with absolute 200 proof ethanol for 3-4 times and methanol for 1 time using a $8 \mathrm{~mL}$ glass vial until the dark brown lower organic phase disappeared, and black $\mathrm{PbS}$ QDs were completely precipitated. The nanoparticles were dried with a stream of $\mathrm{N}_{2}$ and then dissolved in toluene. The concentrations of $\mathrm{PbS}$ NP solutions varied from $2 \mathrm{mg} \mathrm{mL}^{-1}$ to $10 \mathrm{mg} \mathrm{mL}^{-1}$ for the particle sizes of $2.2,2.7,3.1,4.8$, and $14.4 \mathrm{~nm}$.

\section{Centrifuge deposition method}

The centrifuge instrument was manufactured by Thermo Electron Corporation (model: IEC Centra CL2). A general procedure for depositing different colloidal nanoparticle samples using the centrifugation approach is described below. The amount of Au NPs used was calculated based on the amount desired for a specific deposition. In this study, $625 \mu \mathrm{L}$ of $\mathrm{Au} \mathrm{NP}$ solution $(\sim 0.005 \mathrm{M})$ in hexane was mixed with $5 \mathrm{~mL}$ of absolute ethanol. The desired substrate was placed in the bottom of a vial. The vial was then placed in a standard centrifuge with swinging basket and spun for $8 \mathrm{~min}$ at 3,400 rpm (Fig. 2). Before CDM, the sample was sonicated for a half min making sure the nanoparticles were dispersed well in hexane and methanol (or ethanol) mixed solutions. After centrifugation, the
Deposition process

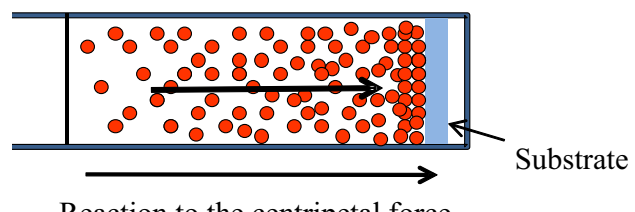

Reaction to the centripetal force

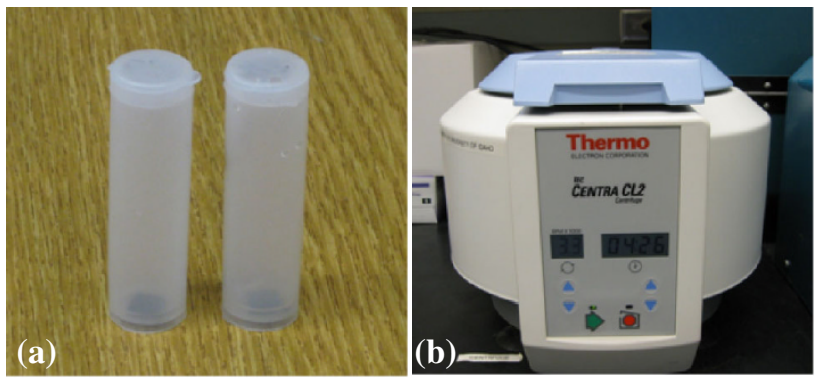

Fig. 2 Top schematic diagram to illustrate the centrifuge deposition process. Bottom a the vials used for the CDM procedure, $\mathbf{b}$ centrifuge instrument used in this study

colorless supernatant was pipetted out and the substrate with the deposited Au NPs was then removed and allowed to air dry for future measurements.

A procedure was also developed for depositing $\mathrm{PbS}$ NPs. The deposition method used is similar to the Au NP deposition described in the previous paragraph. $20 \mu \mathrm{L}$ of $\mathrm{PbS}$ (depending on the concentration synthesized) plus $50 \mu \mathrm{L}$ of toluene were added to prevent premature precipitation, which otherwise leads to uneven coverage. One $\mathrm{mL}$ of methanol was then added to make the particles less soluble in the solution. The vial was then placed in a centrifuge tube and spun, in which it deposited the particles on a substrate placed on the bottom of the vial. The time for the centrifuge was set at $8 \mathrm{~min}$. Using a standard laboratory centrifuge sedimentation at 3,400 rpm which produces approximately $1,950 \mathrm{G}$, the deposition of $4.8 \mathrm{~nm}$ $\mathrm{PbS}$ NPs is complete but the $2.7 \mathrm{~nm} \mathrm{PbS}$ NPs or $2.2 \mathrm{~nm}$ $\mathrm{Au}$ was only partially removed from the solution. An ultra-centrifuge at $10,000 \mathrm{rpm}$ producing over $15,000 \mathrm{G}$ was utilized for the deposition of the $2.7 \mathrm{~nm} \mathrm{PbS}$ or $2.2 \mathrm{~nm}$ Au NPs.

For the deposition on the PET substrate, PbS NPs in toluene, with oleic acid as a capping reagent, were used. $12.5 \mathrm{~mL}$ of the $\mathrm{PbS}$ nanoparticle solution $(4.7 \mathrm{~nm}$, $40 \mathrm{mg} \mathrm{mL}^{-1}$ ) was added to $5 \mathrm{~mL}$ ethanol in a $8 \mathrm{~mL}$ sample vial with the PET substrate. The deposition of the particles was accomplished by centrifuge sedimentation at $3,400 \mathrm{rpm}(\mathrm{G}=1,950)$ for $8 \mathrm{~min}$. After this, the PbS NPcoated film was obtained by removing the solution. Thus, we can directly employ PET as a carrying substrate for the $\mathrm{PbS}$ NP deposition. 

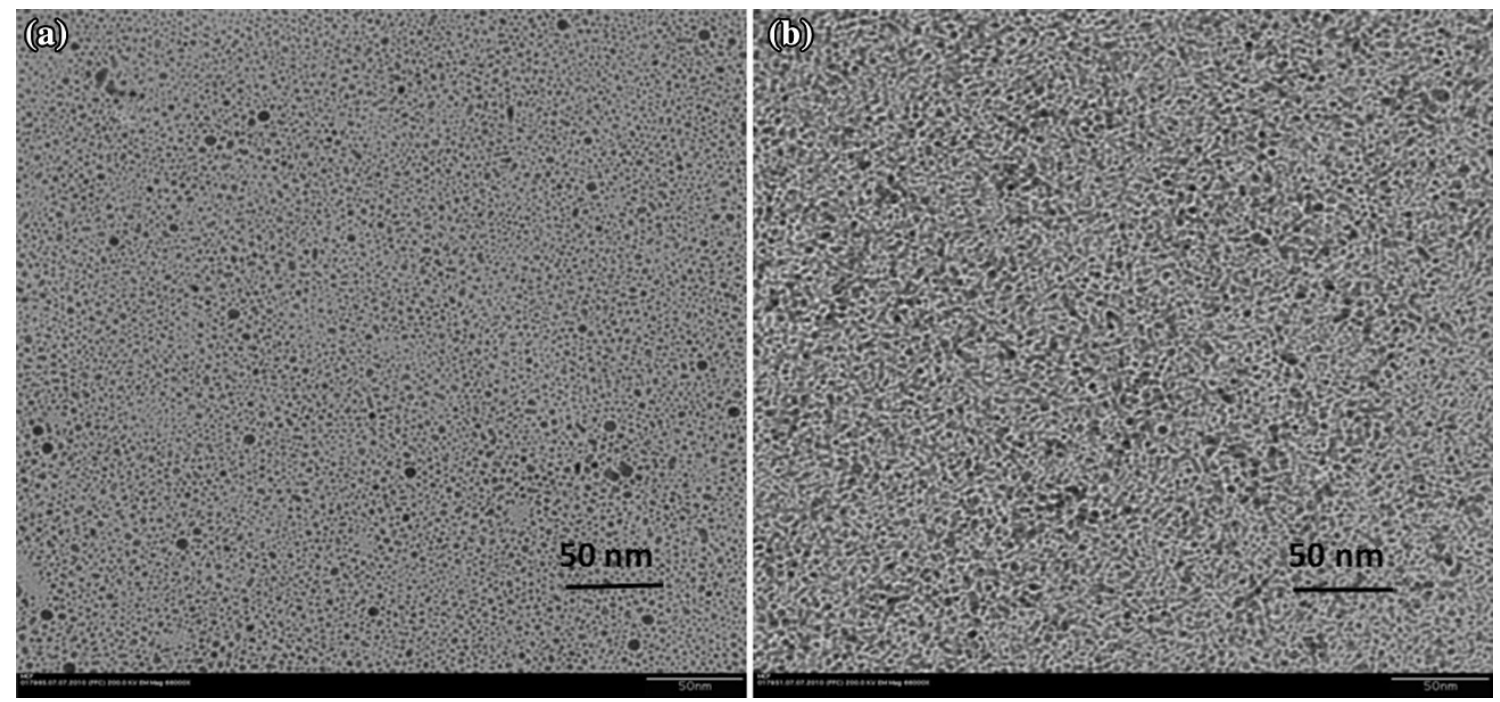

Fig. 3 TEM images of Au NPs $(2.2 \pm 0.37 \mathrm{~nm})$ deposited on carbon-coated Cu grids by CDM. a monolayer and b multilayer

\section{Characterization studies}

TEM analysis

Carbon-coated copper grids purchased from Ted Pella were used to prepare samples for particle size determination from TEM images. The TEM samples were prepared with CDM. A Phillips CM $200 \mathrm{LaB}_{6}$ (lanthanum hexaboride cathode) transmission electron microscope operating at $200 \mathrm{kV}$ was used for both low-and high-resolution imaging. The average size of the PbS NPs was obtained from the TEM images by measuring at least 300 particles using the ImageJ software.

\section{SEM analysis}

Scanning electron microscope images were collected with a Sirion instrument manufactured by FEI, Inc. The following parameters were used for the SEM field emission gun (FEG): an accelerating voltage of $10 \mathrm{kV}$, a spot size of 3.0 , and a working distance of $\sim 4.5 \mathrm{~mm}$.

To define the boundary of $\mathrm{PbS}$ layer when measuring the QD layer cross-section, SEM glue (Kleindiek NanoTechnik, SEM GLU) was injected onto a corner of the Si substrate, a small amount of which was then transferred onto the top layer of $\mathrm{Au}$ or PbS NPs . NOVA SEM (FEI NOVA NanoLab 600 FIB) instrument was employed for this injection. In this process, the SEM glue penetrated into the top layer of QDs to make the QD layer stiff. For some samples, a chemical vapor deposition platinum cap was also used to protect the QDs. The sample surfaces were milled using a FEI StrataDB235 focused ion beam (FIB) with a $30 \mathrm{keV} \mathrm{Ga}$, to produce a few micrometers deep cross-section, which includes the protection layer, nanoparticle layer, and Si surface. Furthermore, a FEI Sirion SEM instrument in conjunction with a back-scattering electron (BSE) detector was used, in which it offers a better definition and contrast between the $\mathrm{Au}$ and PbS NP layers. BSE images are very helpful for obtaining high-resolution compositional maps of a sample and for quickly distinguishing different phases. During the measurement of the cross-section of the films, dynamic focus and tilt correction were applied and specimen tilt was set at $45^{\circ}$. An ultra high-resolution (UHR) mode was turned off due to a faraway working distance (WD $=7.5 \mathrm{~mm}$ ) between the sample and the pole piece of SEM instrument, in which the sample was set at $45^{\circ}$. The magnifications used in SEM images were $20,000 \times$. Because UHR mode was off and magnification was not high enough, nanoparticles could not be observed in detail (Figs. 5, 8).

Surface profilometry, UV-visible, fluorescence, and photoluminescence spectroscopy analyses

The film thickness was also measured with a DekTak $6 \mathrm{M}$ Stylus Profiler instrument. The scan length was $2,500 \mu \mathrm{m}$. UV-Vis-NIR spectra of PbS NPs were obtained using a Cary 5000 Varian UV-Vis-NIR spectrophotometer scanning from 400 to $1,600 \mathrm{~nm}$. Fluorescence spectra were measured with a Horiba Jobin-Yvon Nanolog 916B spectrometer equipped with an IGA 512 InGaAs near-IR detector. The photoluminescence (PL) optical excitation of about $30 \mathrm{~W} / \mathrm{cm}^{2}$ was provided by the $532 \mathrm{~nm}$ continuous wave $(\mathrm{CW})$ emission of a solid-state laser. The PL was measured by a double modulation Fourier transform infrared spectroscopy (FTIR) technique. 


\section{Results and discussion}

Deposition of $\mathrm{Au}$ and PbS NPs using CDM method

Gold and PbS NPs can be homogeneously deposited on a TEM carbon-coated copper grid using the CDM method. The films show similar tightly packed particle arrangements as those prepared by the supercritical fluid $\mathrm{CO}_{2}$ (sc$\mathrm{CO}_{2}$ ) deposition method (Smetana et al. 2008; Wang et al. 2010). As described by previous studies (Smetana et al. 2008; Wang et al. 2010), sc- $\mathrm{CO}_{2}$ deposition requires a high-pressure chamber, specific skill, and a time-consuming process. It will take more than $3 \mathrm{~h}$ to complete the deposition if a volume of a $14 \mathrm{~cm}^{3}$ high-pressure chamber was used. The results in Fig. 3 demonstrate that similar outcomes from the CDM method could be achieved as in sc- $\mathrm{CO}_{2}$ deposition, but with a much faster and simpler procedure.

Figure 3 shows the TEM images of Au NPs $(2.2 \mathrm{~nm})$ deposited by CDM on carbon-coated copper grids with monolayer (Fig. 3a) and multilayer (Fig. 3b) arrangements. The thickness of the film can be varied by changing the concentrations or the volume of the nanoparticle solution. The surface morphology of these films is comparable to the $\mathrm{PbS}$ QD arrays achieved by a sc- $\mathrm{CO}_{2}$ fluid deposition process (Smetana et al. 2008; Wang et al. 2010) including those reported on a GaAs substrate (Ullrich et al. 2010). In general, the images of the Au and PbS NP films deposited by the CDM procedure reveal fairly homogenous coverage on different substrates.

The deposition of mixed solutions of two different types, or different sizes, of nanoparticles using the CDM method was also studied. One experiment was the deposition of a mixture of small Au NPs $(2.2 \mathrm{~nm})$ and large PbS NPs (14.4 $\mathrm{nm}$, in a low concentration) on copper grids by the CDM method. A similar experiment, i.e., a mixture of small PbS NPs (3.1 nm) and large PbS NPs (14.4 nm, in a low concentration) deposited on $\mathrm{Cu}$ grids, was also carried out by this method. Similar outcomes, revealed by TEM images, were observed for the above two experiments. The TEM image shows an even surface coverage by the Au or small PbS (3.1 nm) nanoparticle layer. The larger PbS NPs do not seem to cluster together but to be randomly dispersed among the $\mathrm{Au}$ or $\mathrm{PbS}(3.1 \mathrm{~nm})$ nanoparticle layer. When $\mathrm{Au}$ or PbS NPs were deposited individually using $\mathrm{CDM}$ at a low concentration, the majority was in close proximity over large areas but there were some scattered void areas. When the concentration of nanoparticles was increased, the substrates showed fairly even coverage after deposition. When the films were deposited using a mixture of two different-sized nanoparticles, it was not known if the large particles would deposit first due to their larger mass being more affected by the reaction to the centripetal force. The TEM image showing the larger particles ( $\mathrm{PbS}$, $14.4 \mathrm{~nm}$ ) dispersion within the smaller particles (Au, $2.2 \mathrm{~nm}$, or $\mathrm{PbS}, 3.1 \mathrm{~nm}$ ) suggests that this may not be the case (Fig. 4a). Figure $4 \mathrm{~b}$ shows a TEM image of a mixture of 2.7 and $4.8 \mathrm{~nm} \mathrm{PbS} \mathrm{NPs.} \mathrm{For} \mathrm{the} \mathrm{mixed} \mathrm{nanoparticles,} \mathrm{as}$ with $\mathrm{Au}$ and $\mathrm{PbS}$ NPs, or two different-sized PbS NPs, $50 \mu \mathrm{L}$ of toluene was added to the PbS sample first before adding the second compound. Five $\mathrm{mL}$ of ethanol was then added to the particle mixture before centrifugation. This procedure seems to result in random distribution of both components in the film.
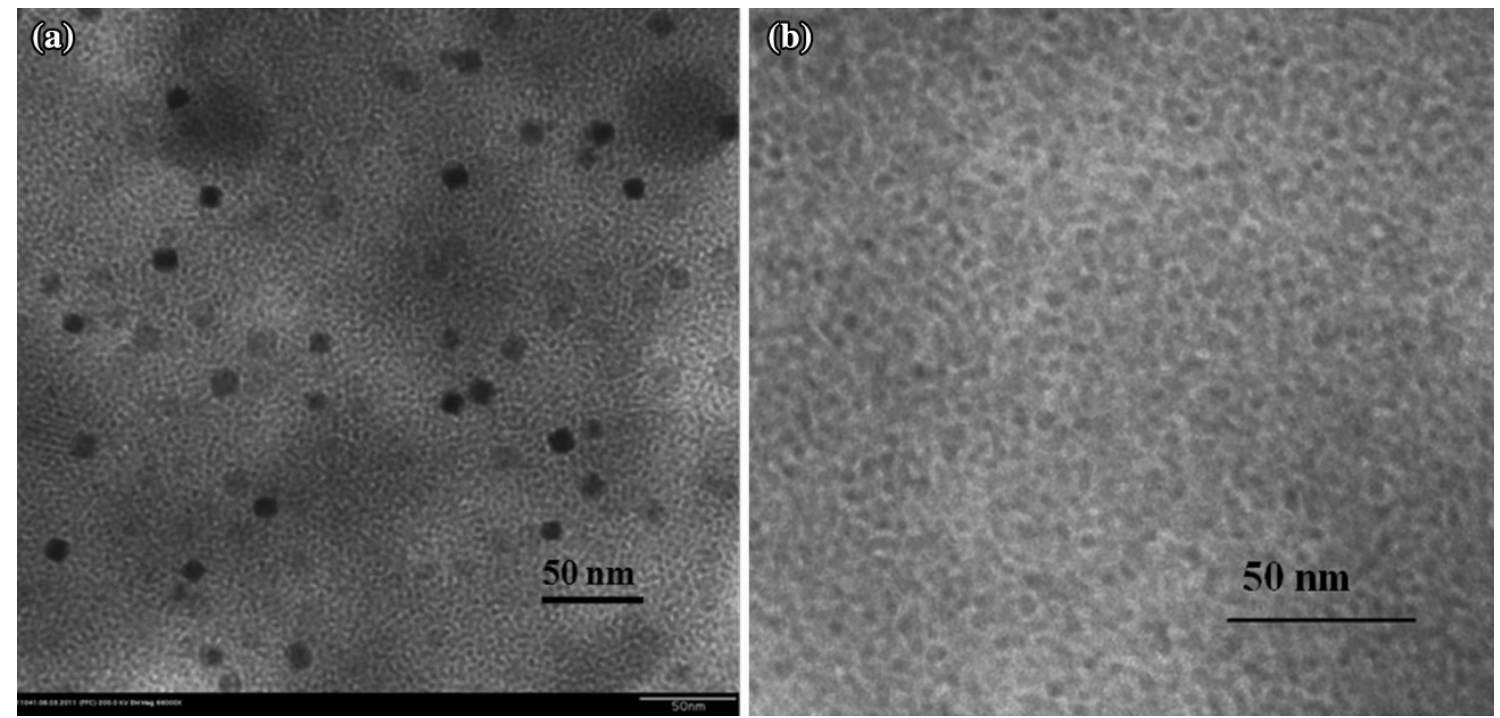

Fig. 4 a TEM image of PbS NPs (14.4 nm) and Au NPs (2.2 nm) mixed and then deposited, showing the dispersion of the large particles within the smaller particles. b TEM image of PbS deposited on a TEM grid using CDM method showing a mixture of 2.7 and $4.8 \mathrm{~nm}$ of PbS NPs 


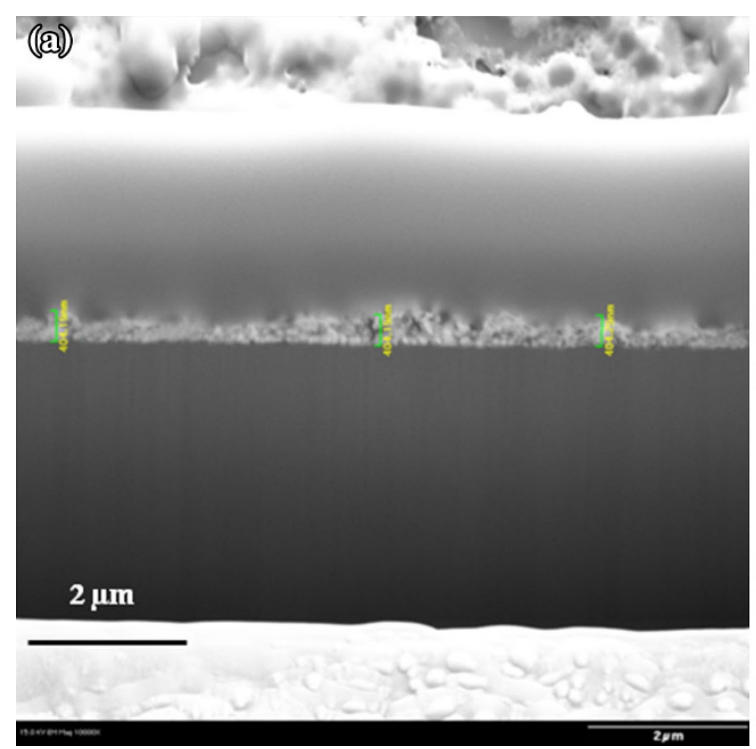

Fig. 5 SEM images of a a cross-section of a single Au layer film, the thickness is $\sim 400 \mathrm{~nm}, \mathbf{b}$ a cross-section of a double-layer film, the thickness of Au layer (bottom) is about $430 \mathrm{~nm}$, and $\mathrm{PbS}$ layer (top) is

To demonstrate the fabrication of double-layer films on a solid surface, a single layer of Au NPs was deposited on a piece of silicon, and the remaining liquid was then removed. The sample was left to dry overnight. Afterwards, the second solution containing PbS NPs was added and the CDM procedure was repeated to make the second layer. Figure 5 shows cross-sections of SEM images of a single $\mathrm{Au}$ NP layer $(\sim 400 \mathrm{~nm})$ deposited by CDM (Fig. 5a), and a double-layer film (Fig. 5b) made with a PbS NP layer (4.7 nm, thickness of $\sim 500 \mathrm{~nm}$ ) deposited on the top of the Au NP layer $(2.2 \mathrm{~nm}$, thickness of $\sim 430 \mathrm{~nm}$ ) applying the CDM procedure. The back-scattering electron detector shows the SEM image with distinct contrast between the two layers (Fig. 5).

Control of film coverage at low population of nanoparticles was demonstrated by TEM images. Figure 6 shows when the volume of Au NP added increases, the coverage or the thickness of the Au NP in the CDM process can be increased as well. As shown in Fig. 6a, when $10 \mu \mathrm{L}$ of $\mathrm{Au}$ NP was used, the films (on TEM grids) showed randomly scattered islands. When $40 \mu \mathrm{L}$ (Fig. 6b) and $80 \mu \mathrm{L}$ (Fig. 6c) Au NPs were added separately in CDM, relatively dense (Fig. 6b) and monolayer (Fig. 6c) distributions could be observed. When more Au NPs, for example, $200 \mu \mathrm{L}$ (Fig. 6d) was added in CDM, thick films can be formed. However, the multilayer creates a hindrance for clear observation of nanoparticles from TEM. For the image in Fig. 6d, when $200 \mu \mathrm{L}$ NP solution was added, an area at the edge of uniform coverage was selected where the voids allow the film thickness to be imaged. Nevertheless, the process of the film formation by $\mathrm{CDM}$ with increasing amount of the Au NPs is clearly illustrated in Fig. 6.

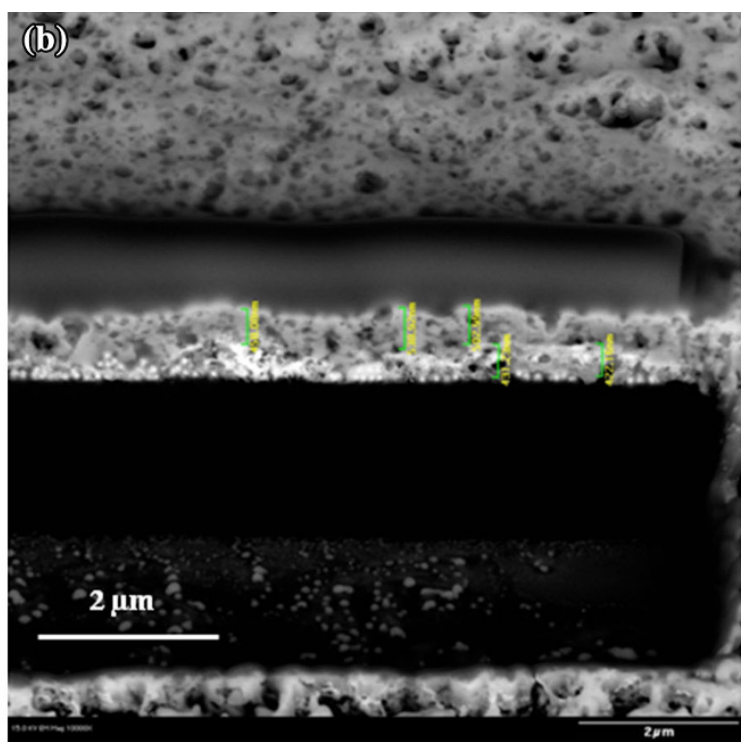

about $500 \mathrm{~nm}$. The green lines shown on the cross-section in SEM images are measuring bars

Film thickness measurements

The film thickness was measured with a DekTak $6 \mathrm{M}$ Stylus Profiler instrument as well. Figure 7 shows the thickness measurements of the Au NP films. The scan length was $2500 \mu \mathrm{m}$. The film thickness [average scan height $(\mathrm{ASH})]$ of $\mathrm{Au} \mathrm{NP}$ on $\mathrm{Si}$ substrate is $2.02 \mathrm{~K} \AA$ (202 nm, Fig. 7a), $5.10 \mathrm{~K} \AA$ (510 nm, Fig. 7b), and $10.32 \mathrm{~K} \AA(1,032 \mathrm{~nm}$, Fig. 7c) for films a, b and c, respectively. The volumes of the Au NP solution used in films a, b and c were 20,200 and $400 \mu \mathrm{L}$, respectively, corresponding to the ratio of 1:10:20. Based upon the thickness data, the thickness ratio for films $b$ and $c$ is quite proportional to the relative amounts of the Au NP solution added, i.e., when the volume increases by a factor of 2 (from 200 to $400 \mu \mathrm{L}$ ), the film thickness doubles from $510 \mathrm{~nm}$ to $1,032 \mathrm{~nm}$. However, from 20 to $200 \mu \mathrm{L}$, the film thickness acquired is not proportional to the Au NP solution added. This is likely due to the fact that the population of the NPs is not high enough to cover the substrate surface and only island-like structures are formed. Only when the population of the $\mathrm{Au}$ nanoparticles is high enough to form at least a monolayer film, then the thickness of the film is proportional to the volume of NP added. The average scan height is between 200 and $1,000 \mathrm{~nm}$, whereas the scan length is $2,500 \mu \mathrm{m}$ $(2.5 \mathrm{~mm})$. It provides sufficient information for measuring the layer thickness. The reaction to the centripetal force allows a random and even scattering deposition on the substrates. If the scan height measured was $1,000 \mathrm{~nm}$, the ratio of the scan length to array scan height will be a factor of 2,500 . 

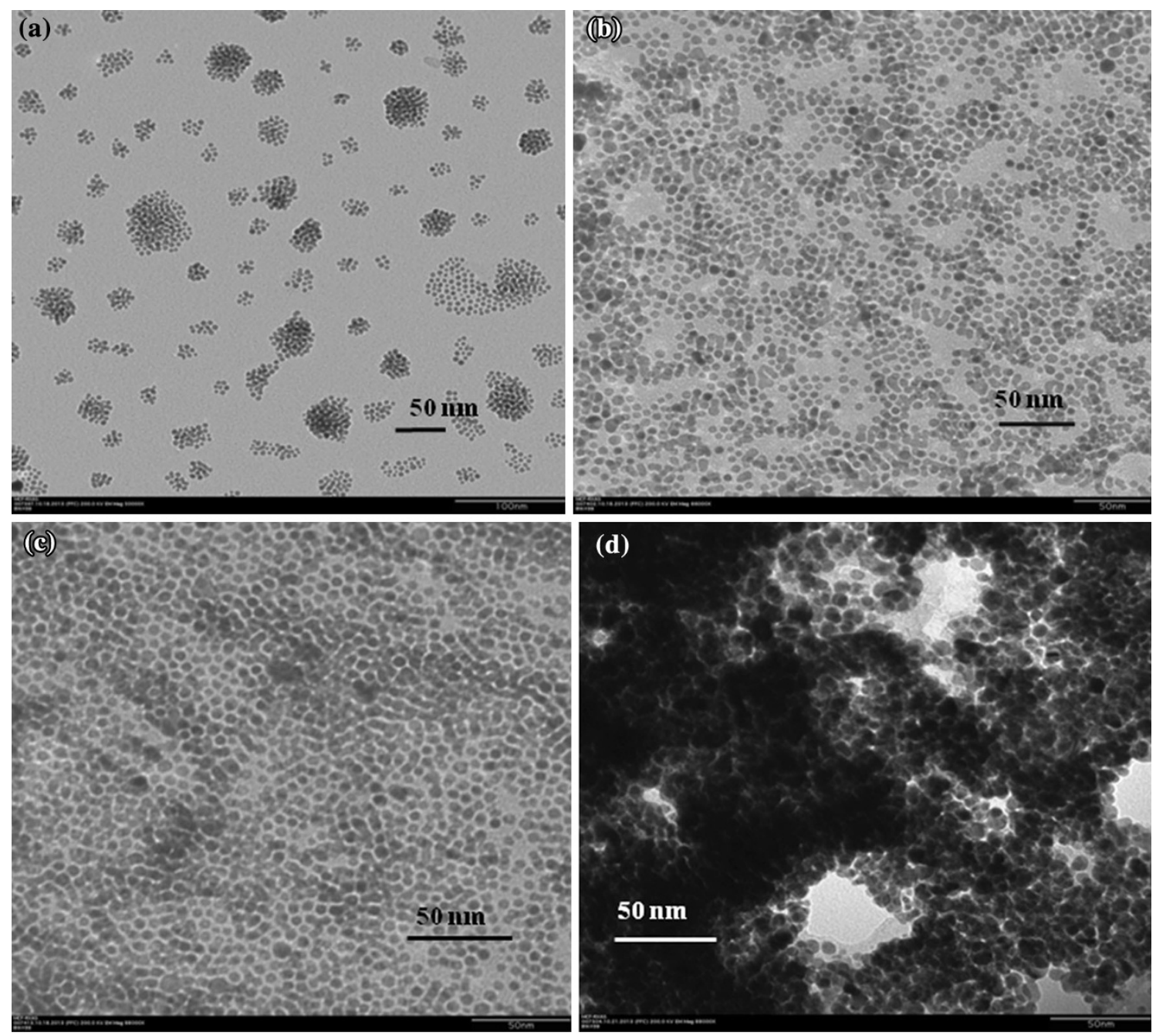

Fig. 6 TEM images of a $10 \mu \mathrm{L}$, b $40 \mu \mathrm{L}$, c $80 \mu \mathrm{L}$, and d $200 \mu \mathrm{L}$ Au NPs added in CDM processes

To check the consistency of film thickness, the crosssections of the Au film were also measured by SEM as shown in Fig. 8. Au NP volume ratios used for making these films are 1:10:20. The average cross-section thicknesses of the Au films measured with the Sirion SEM instrument displayed in Fig. 8a-c were 157, 404, and $804 \mathrm{~nm}$, corresponding to the Au NP solution ratios of $20 \mu \mathrm{L}: 200 \mu \mathrm{L}: 400 \mu \mathrm{L}$, respectively. The thickness outcomes in relative values are consistent with the results obtained from DekTak 6 M Stylus Profiler instrument.

In previous works combining PET and PbS NPs, the PbS NPs were either embedded in polymers or the PET was used as a carrier for Fano filters containing PbS NPs (Binder et al. 2006, 2009), which is much more tedious than this simple centrifuge sedimentation method. The adhesion between NPs and substrate was tested by different methods. All the nanoparticles adhered firmly to the substrates, albeit with different strengths. The nanoparticle films formed in this way did not peel off during bending, mechanical abrasion, and exposure to solvents. When deposited on a flexible substrate like plastic sheet, we simply bent the plastic by hand and the films did not visibly flake off or crack. The PbS NPs deposited on PET sheet could not be removed by Scotch tape. On the other hand, the PbS NPs deposited on glass could be removed somewhat using Scotch tape. However, when a layer of Au NPs was first applied on the glass, the PbS NP layer on top was not readily removed. When the metal nanoparticles were deposited on silicon wafers, there was also no noticeable removal of the Au NPs when the tape was peeled off from the wafer. The nanoparticles also cannot be removed from the wafer when exposed to solvents such as acetone and ethanol. We do not know the bonding specifics between the nanoparticles and PET, but nanoparticles can bind to polymeric surfaces through van der Waals forces (Min et al. 2008), hydrogen bonding (Binder et al. 2006), electrostatic linkage (Kinge et al. 2008), and covalent bonding (Li et al. 2010). Furthermore, ligand-stabilized 
Fig. 7 Thickness

measurements of Au NP films on silicon surface $\left(5 \times 5 \mathrm{~mm}^{2}\right)$.

The scan length was $2,500 \mu \mathrm{m}$. The plots on the top are the thickness [average scan height $(\mathrm{ASH})]$ measurements and the measurements of a $202 \mathrm{~nm}$, b $510 \mathrm{~nm}$, and c $1,032 \mathrm{~nm}$ from the top correspond to films $\mathbf{a}, \mathbf{b}$, and $\mathbf{c}$ in the images, respectively
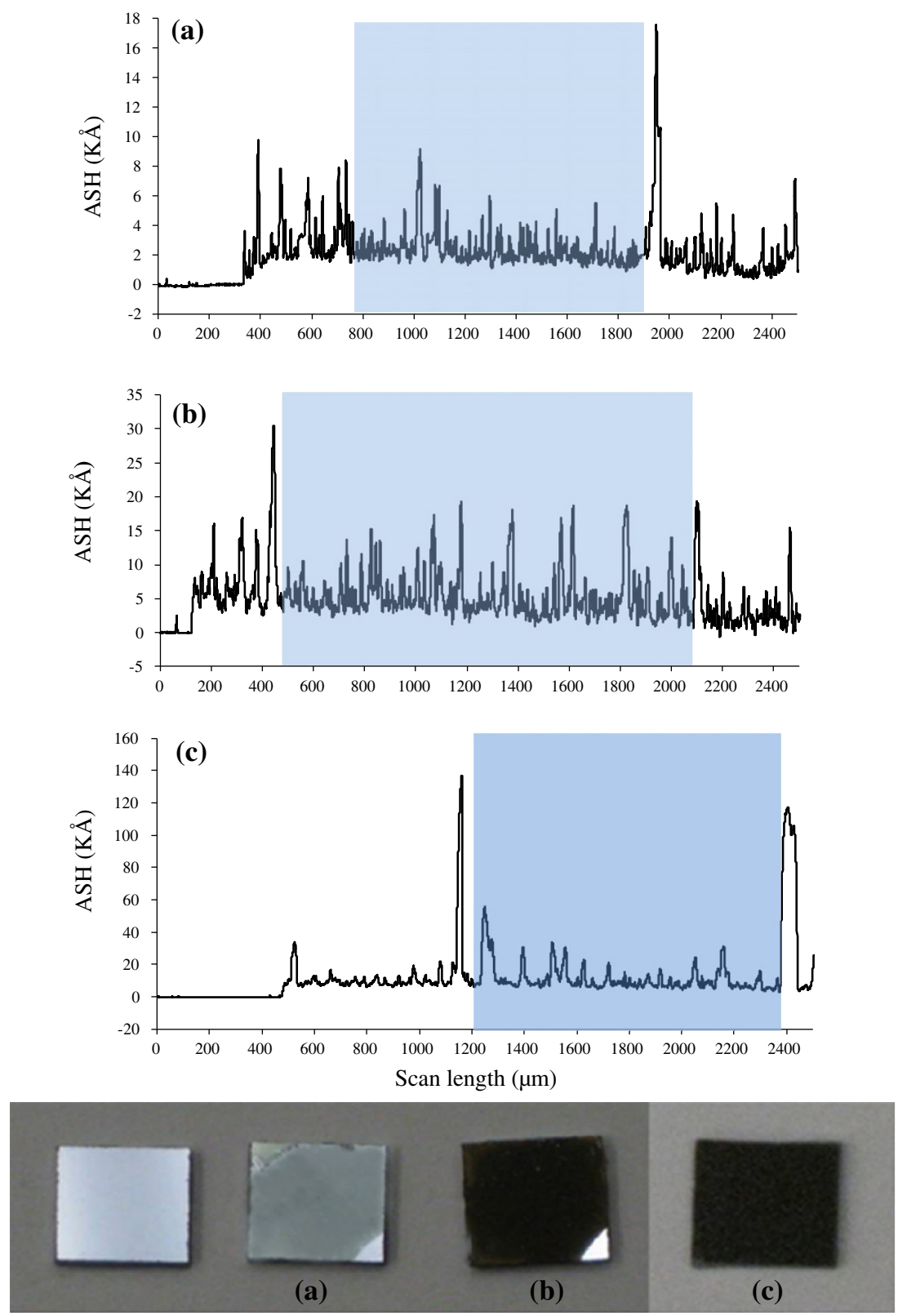

Si substrate $\quad$ Film a $(20 \mu \mathrm{L}) \quad$ Film b $(200 \mu \mathrm{L}) \quad$ Film c $(400 \mu \mathrm{L})$ nanoparticles are able to bond to specific sites on monomers (Haryono and Binder 2006).

\section{Spectroscopy studies}

Photoluminescence studies of PbS/PET

For the PL experiments, the optical excitation of about $30 \mathrm{~W} / \mathrm{cm}^{2}$ was provided by the $532 \mathrm{~nm}$ continuous wave (cw) emission of a solid-state laser. The PL was measured by a double modulation Fourier transform infrared spectroscopy (FTIR) technique. The double modulation technique was necessary due to the rather weak PL signal of the sample at room temperature. The PL spectra were recorded using a nitrogen cooled InGaAs detector and a quartz beamsplitter in the Bomem DA3 FTIR from $5 \mathrm{~K}$ up to $300 \mathrm{~K}$ using a closed-cycle refrigeration cryostat with a diamond window. Figure 9 shows the PL spectra of $\mathrm{PbS} / \mathrm{PET}$ deposited using $\mathrm{CDM}$ measured at $5 \mathrm{~K}$ and $300 \mathrm{~K}$. The broken line represents the measured PL intensity $(I)$ as a function of the emitted photon energy $(h v)$ and the solid line fits using the Gaussian intensity distribution,

$I(h v)=A \times \exp \left(-\left(h v-h v_{\mathrm{p}}\right)^{2} /\left(2 w^{2}\right)\right)$ 


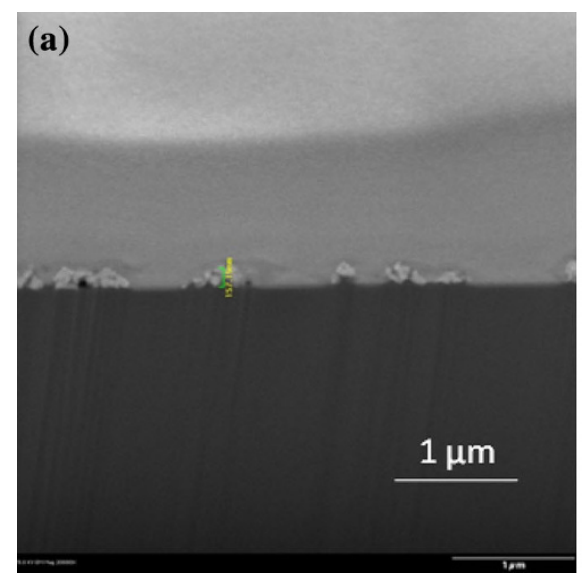

(b)

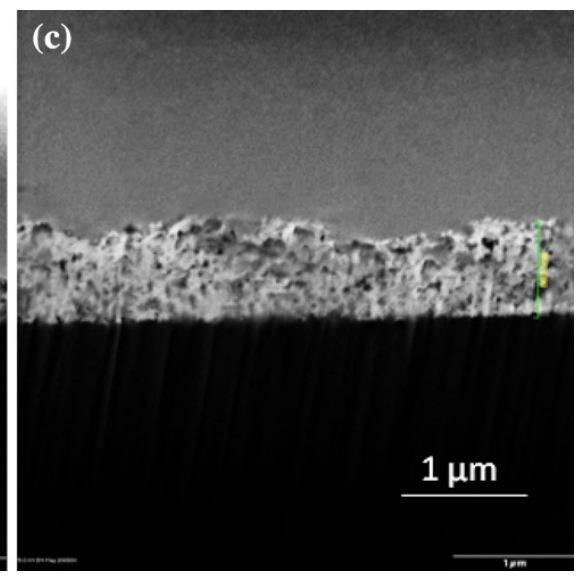

Fig. 8 SEM of Au layer cross-section, Au NP volume ratios added are 1:10:20. SEM magnifications are all $\times 20,000$. Cross-sections in a-c are 157, 404, and $804 \mathrm{~nm}$, respectively. The green lines shown on the cross-section in SEM images are measuring bars
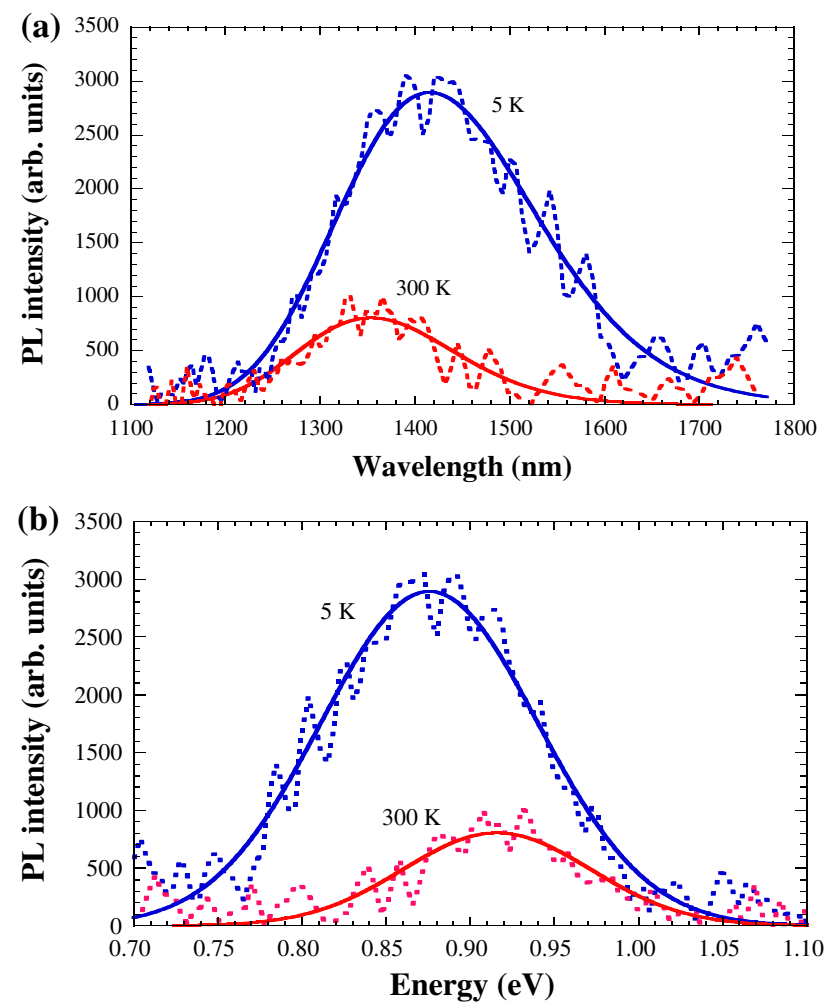

Fig. 9 The PL intensity a vs. wavelength and b vs. energyof PbS/ PET deposited using CDM. The broken lines represent the measured PL intensity and solid lines represent the fits using Eq. (1)

where $A$ is the peak height, $h v_{\mathrm{p}}$ is the center energy of the PL peak, and $w$ defines the peak width parameter, which is related to the full-width at half maximum (FWHM) by FWHM $=2.35 \times w$. The peak intensity at $5 \mathrm{~K}$ is significantly enhanced, while the PL emission is weaker at $300 \mathrm{~K}$, as expected, the decrease is less than an order of magnitude. The $61 \mathrm{~nm}(40 \mathrm{meV})$ PL peak shift from 5 to $300 \mathrm{~K}$ in PbS QDs/PET sample observed (Fig. 9a, b) is

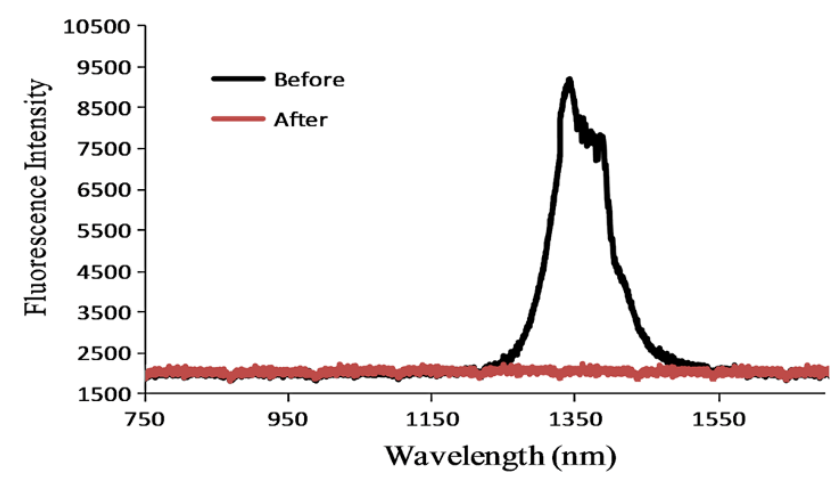

Fig. 10 Fluorescence of a $\mathrm{PbS}$ nanoparticle solution before and after CDM

comparable to the $42 \mathrm{~nm}(30 \mathrm{meV})$ shift in the PbS/glass absorption peak (Ullrich et al. 2012). We also noticed that the PbS/PET data of PL peak position $(\mathrm{eV})$ versus temperature $(\mathrm{K})$ are more scattered than other fits reported previously (Ullrich et al. 2011). Therefore, it is possible that colloidal PbS QDs on PET substrates deposited by $\mathrm{CDM}$ are subject to photo-induced changes under laser irradiation more than $\mathrm{PbS}$ QDs on inert substrates such as glass, suggesting the established bonding linkage at the PET surface was built-up during CDM deposition.

Fluorescence measurements

Fluorescence spectroscopy was used to characterize the film and solution samples. A fluorescence spectrum of a $\mathrm{PbS}$ nanoparticle solution before deposition was measured. The spectrum shows a substantial emission peak around $1350 \mathrm{~nm}$. Following deposition of $\mathrm{PbS}$ on glass by the CDM method, another spectrum of the centrifuged solution in the vial was taken to determine the concentration of the PbS NPs left in the solution (Fig. 10). As shown in Fig. 10, there is virtually no fluorescence feature for the solution 


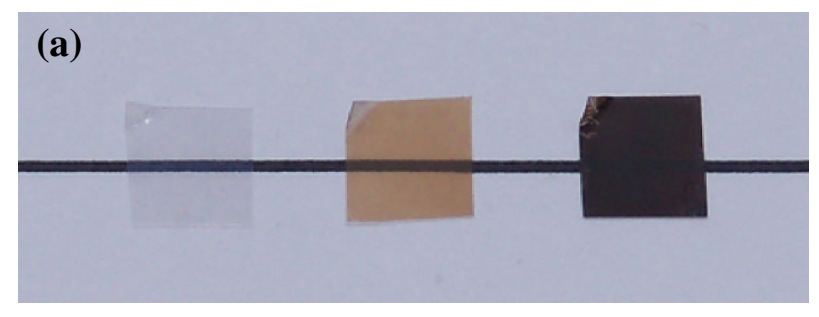

(b)

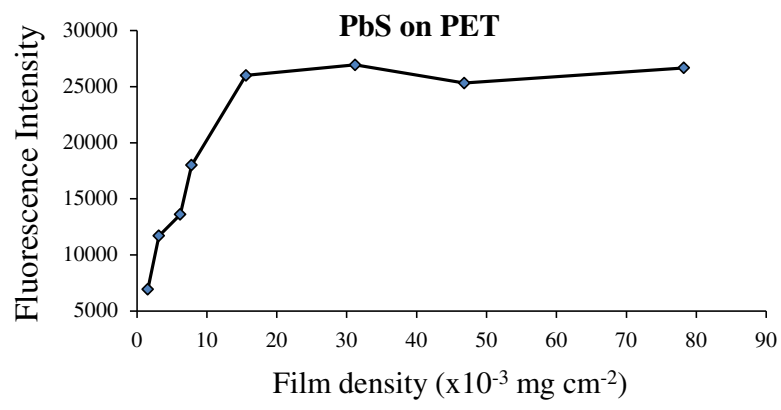

(c)

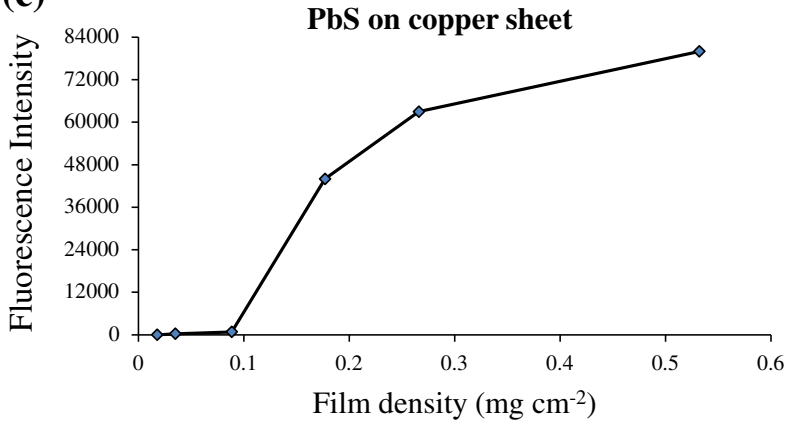

Fig. 11 a Optical images of PET with increasing coverage of $\mathrm{PbS}$ QDs (from left to right: $8.8 \times 10^{-3}, 44 \times 10^{-3}$, and $440 \times 10^{-3}$ $\mathrm{mg} \mathrm{cm}{ }^{-2}$, respectively. Concentration ratio $\left.=1: 5: 50\right)$. Fluorescence intensities as a function of $\mathrm{PbS}$ nanoparticle concentrations $\mathbf{b}$ on a PET film and $\mathbf{c}$ on a copper sheet

after the deposition indicating that essentially all PbS NPs are removed from the solution using the CDM method.

When the concentration of $\mathrm{PbS}$ NPs in solution is increased, the amount of particles deposited on the surface of the sample, after the CDM process, also increases. This increase in PbS NPs deposited on the PET substrate leads to a visually darker sample (Fig. 11a) and the expected increase in fluorescence intensities (Fig. 11b). At a film density of about $0.016 \mathrm{mg} \mathrm{cm}^{-2}$ or greater, the fluorescence intensity ceases to increase indicating that this is the film thickness which contributes to the fluorescence of $\mathrm{PbS}$ NPs (Fig. 11b). With films of PbS NPs deposited on a copper sheet, the fluorescence of the $\mathrm{PbS}$ particles is completely quenched until the film density is about $0.1 \mathrm{mg} \mathrm{cm}{ }^{-2}$ or greater (Fig. 11c). As noted by Guo (2008), substrates are known to play an active role in the fluorescence of semiconductor nanoparticles. Metal

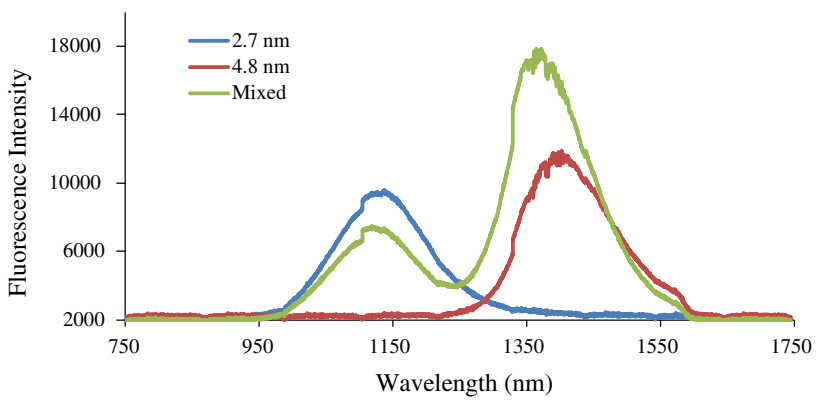

Fig. 12 Fluorescence spectra of $\mathrm{PbS}$ QD films made of individual and a mixed sample solutions with 2.7 and $4.8 \mathrm{~nm}$ QDs

surfaces are known to have a quenching effect on nanoparticle fluorescence signals (Ganesh et al. 2008; Matsuda et al. 2008). The quenching of the fluorescence is probably due to energy transfer from the PbS NPs to the metal substrate resulting in a diminished emission (Dulkeith et al. 2001, 2002). Above $0.1 \mathrm{mg} \mathrm{cm}^{-2}$, the fluorescence of the $\mathrm{PbS}$ NPs on the copper sheet can be detected and the intensity of the fluorescence continues to increase up to $0.54 \mathrm{mg} \mathrm{cm}^{-2}$. For PbS NPs in contact with a conductive metal such as copper, the effective range of the quenching effect is about $0.1 \mathrm{mg} \mathrm{cm}^{-2}$.

\section{Energy transfer}

Energy transfer between semiconductor nanoparticles of difference sizes is of current interest and more understanding of this phenomenon is needed (Stephen et al. 2007). Most energy transfer studies are done in composites using solvent evaporation or crude deposition processes (Kagen et al. 1996; Stephen et al. 2007). In this study, we used the CMD method to deposit a mixture of two different sizes of PbS NPs (2.7 and $4.8 \mathrm{~nm}$ ) on PET. The particles were deposited individually to determine the initial intensity of each size of PbS NPs separately. The two size particles were then mixed and deposited as a mixed film. The fluorescence spectra for these samples are given in Fig. 12. The individually deposited particles have an intensity ratio of $1(2.7 \mathrm{~nm}): 1.3(4.8 \mathrm{~nm})$. In the mixed nanoparticle film, the fluorescence peak of the $2.7 \mathrm{~nm}$ QDs decreased and the peak for the $4.8 \mathrm{~nm}$ QDs increased. Obviously, energy transfer occurred between the PbS QDs with different sizes, the small dots $(2.7 \mathrm{~nm})$ serving as energy donors and the large ones $(4.8 \mathrm{~nm})$ as acceptors. This energy transfer resulted in a new emission intensity ratio of $1(2.7 \mathrm{~nm}): 3(4.8 \mathrm{~nm})$ as shown in Fig. 12.

The energy transfer between PbS NPs appears to depend on the concentration per $\mathrm{cm}^{2}$ of the film prepared by the CDM method. Figure 13 shows two cases, one sample with a mixed $\mathrm{PbS}$ nanoparticles $(2.7$ and $4.8 \mathrm{~nm})$ at $0.05 \mathrm{mg} \mathrm{cm}^{-2}$ and the other at $0.25 \mathrm{mg} \mathrm{cm}^{-2}$; both 

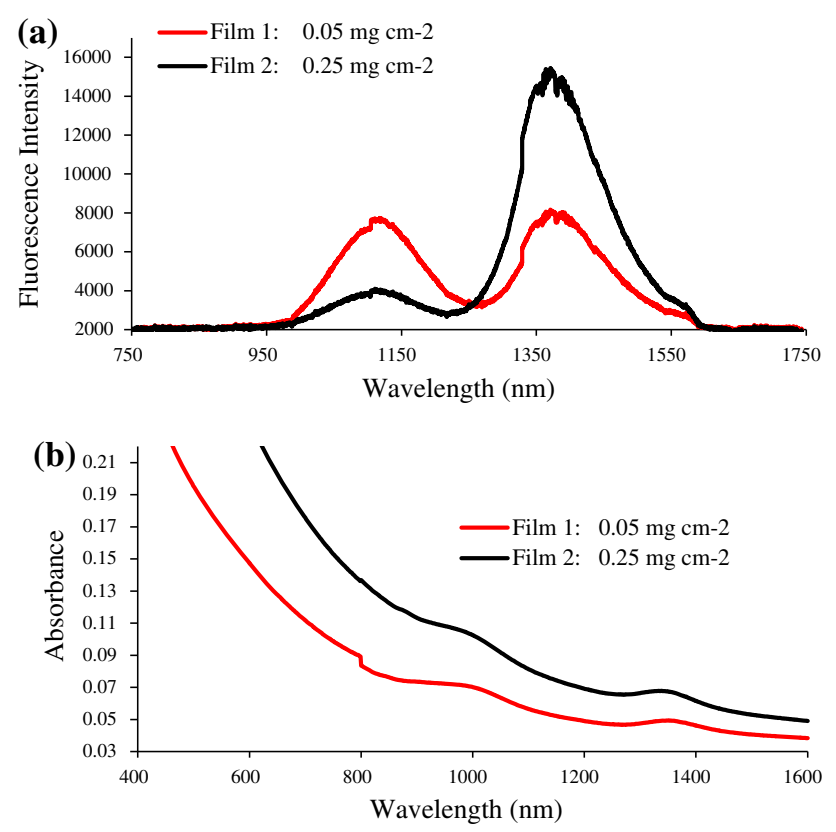

Fig. 13 a Fluorescence and $\mathbf{b}$ absorbance spectra of $\mathrm{PbS}$ nanoparticle films made of a mixture of 2.7 and $4.8 \mathrm{~nm}$ sized QDs. Film 2 $\left(0.25 \mathrm{mg} \mathrm{cm}^{-2}\right)$ has 5 times more areal density than that of film 1 $\left(0.05 \mathrm{mg} \mathrm{cm}^{-2}\right)$

samples were prepared from the same mixed solution. As shown in Fig. 13a, the fluorescence peak ratio for sample 1 is about $1(2.7 \mathrm{~nm}): 1(4.8 \mathrm{~nm})$ for the $1,130 \mathrm{~nm} / 1,390 \mathrm{~nm}$ peaks, whereas in sample 2 this ratio is $1(2.7 \mathrm{~nm}): 8$ $(4.8 \mathrm{~nm})$. Energy transfer from the smaller $\mathrm{PbS}$ particles $(2.7 \mathrm{~nm})$ to the larger $\mathrm{PbS}$ particles $(4.8 \mathrm{~nm})$ appears more efficient for the sample with more PbS NPs per square centimeter. A more closely packed PbS NP film would facilitate energy transfer from smaller (higher energy bandgap) to larger (lower energy bandgap) QDs. As expected, the absorption spectra of the two samples in the visible and NIR regions show about the same ratio for the two PbS NP peaks regardless of the amount deposited per square centimeter (Fig. 13b). The peak absorbance maxima centered around 1,000 and 1,350 nm, for 2.7 and $4.8 \mathrm{~nm}$ QDs, respectively (Fig. 13b). Details about the experiments performed and results obtained related to fluorescence resonance energy transfer (FRET) involving $\mathrm{PbS}$ QDs can be found in the literature published by us previously (Wang et al. 2012).

\section{Conclusion}

A simple, fast, and straightforward centrifuge deposition method has been developed for making uniform nanoparticle films from colloidal solutions. The deposition involves common laboratory equipment and solvents. This method is able to deposit uniform films of different types of colloidal nanoparticles on a variety of substrates. The substrates can be varied from flexible to rigid sheets, from flat to rough and uneven surfaces, and from insulator to conductive materials. The nanoparticle films prepared by this method show good stability and affinity to the substrate surfaces. The adhesion between $\mathrm{Au}$ and $\mathrm{PbS}$ is fairly good. This CDM technique is suitable for making relatively thick films. The thickness of the nanoparticle films can be controlled by the concentration or the volume of the colloidal nanoparticle solutions. The CDM method can also make films of mixed nanoparticles and layered nanoparticles. The centrifuge deposition technique appears to provide a simple method for making uniform nanoparticle films on different substrate surfaces for chemical and optical property studies.

Acknowledgments We are grateful to Scott Apt at Material Characterization Facility at Air Force Research Laboratories for his helpful assistance with acquiring SEM cross-section images.

Open Access This article is distributed under the terms of the Creative Commons Attribution License which permits any use, distribution, and reproduction in any medium, provided the original author(s) and the source are credited.

\section{References}

Ahmadi R, Ehsani N, Soltani AK (2013) Carbon coating graphite substrates using centrifugal deposition process: effect of centrifugal rotation speed and heat treatment on coating quality. Middle East J Sci Res 15(2):287-290

Aziz MJ (2008) Film growth mechanisms in pulsed laser deposition. Appl Phys A 93:579-587

Bakueva L, Konstantatos G, Levina L, Musikhin S, Sargent EH (2004) Luminescence from processible quantum dot-polymer light emitters 1100-1600 nm: tailoring spectral width and shape. Appl Phys Lett 84:3459-3461

Binder WH, Kluger C, Josipovic M, Straif CJ, Friedbacher G (2006) Directing supramolecular nanoparticle binding onto polymer films: film formation and influence of receptor density on binding densities. Macromolecules 39:8092-8101

Binder WH, Lomoschitz M, Sachsenhofer R, Friedbacher G (2009) Reversible and irreversible binding of nanoparticles to polymeric surfaces. J Nanomater, Article ID 613813

Brodsky MH, Cardona M, Cuomo JJ (1977) Infrared and Raman spectra of the silicon-hydrogen bonds in amorphous silicon prepared by glow discharge and sputtering. Phys Rev B 16:3556-3571

Bruchez M Jr, Moronne M, Gin P, Weiss S, Alivisatos AP (1998) Semiconductor nanocrystals as fluorescent biological labels. Science 281:2013-2016

Chang JF, Sun BQ, Breiby DW, Nielsen MM, Solling TI, Giles M, McCulloch I, Sirringhaus H (2004) Enhanced mobility of poly(3-hexylthiophene) transistors by spin-coating form highboiling point solvents. Chem Mater 16(23):4772-4776

Chou SY, Krauss PR, Zhang W, Guo L, Zhuang L (1997) Sub-10 nm imprint lithography and applications. J Vac Sci Technol B 15(6):2897-2904

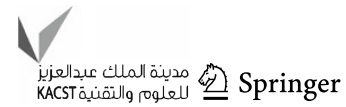


Colvin VL, Schlamp MC, Alivisatos AP (1994) Light-emitting diodes made from cadmium selenide nanocrystals and a semiconducting polymer. Nature 370:354-357

Decher D, Eckle M, Schmitt J, Struth B (1998) Layer-by-layer assembled multicomposite films. Curr Opin Colloid Interface Sci 3:32-39

Dulkeith E, Morteani A, Sonnichsen C, Feldmann J, Riethmuller S, Spatz JP, Moller M (2001) Fluorescence quenching in the vicinity of metal nanoparticles. American Physical Society annual March meeting, March 12-16, APS, Seattle, ID: MAR01, abstract \# C14.006

Dulkeith E, Morteani AC, Niedereichholz T, Klar TA, Feldmann J, Levi SA, van Veggel FCJM, Reinhoudt DN, Moller M, Gittins DI (2002) Fluorescence quenching of dye molecules near gold nanoparticles: radiative and nonradiative effects. Phys Rev Lett 89:203002(1)-203002(4)

Ganesh N, Mathias PC, Zhang W, Cunningham BT (2008) Distance dependence of fluorescence enhancement from photonic crystal surfaces. J Appl Phys 103:083104(1)-083104(6)

Guo S, Tsai S, Kan H, Tsai D, Zachariah MR, Phaneuf RJ (2008) The effect of an active substrate on nanoparticle-enhanced fluorescence. Adv Mater 20:1424-1428

Haryono A, Binder WH (2006) Controlled arrangement of nanoparticle arrays in block-copolymer domains. Small 2:600-611

Hines MA, Scholes GD (2003) Colloidal PbS nanocrystals with sizetunable near-infrared emission: observation of post-synthesis self-narrowing of the particle size distribution. Adv Mater 15(21):1844-1849

Huynh WU, Dittmer JJ, Alivisatos AP (2002) Hybrid nanorodpolymer solar cells. Science 295:2425-2427

Kagen CR, Murray CB, Bawendi MG (1996) Long-range resonance transfer of electronic excitations in close-packed CdSe quantumdot solids. Phys Rev B 54:8633-8644

Kinge S, Crego-Calama M, Reinhoudt DN (2008) Self-assembling nanoparticles at surfaces and interfaces. Chem Phys Chem 9:20-42

Kong YC, Yu DP, Zhang B, Fang W, Feng SQ (2001) Ultravioletemitting $\mathrm{ZnO}$ nanowires synthesized by a physical vapor deposition approach. Appl Phys Lett 78:407-409

Li S, Lin MM, Toprak MS, Kim DK, Muhammed M (2010) Nanocomposites of polymer and inorganic nanoparticles for optical and magnetic applications. Nano Rev 1:5214(1)5214(19)

Matsuda K, Ito Y, Kanemitsu Y (2008) Photoluminescence enhancement and quenching of single $\mathrm{CdSe} / \mathrm{ZnS}$ nanocrystals on metal surfaces dominated by plasmon resonant energy transfer. Appl Phys Lett 92:211911(1)-211911(3)

Medintz IL, Uyeda HT, Goldman ER, Mattoussi H (2005) Quantum dot bioconjugates for imaging, labelling and sensing. Nat Mater 4:435-436
Michalet X, Pinaud FF, Bentolila LA, Tsay JM, Doose S, Li JJ, Sundaresan G, Wu AM, Gambhir SS, Weiss S (2005) Quantum dots for live cells, in vivo imaging, and diagnostics. Science 307:538-544

Min Y, Akbulut M, Kristiansen K, Golan Y, Israelachvili J (2008) The role of interparticle and external forces in nanoparticle assembly. Nat Mater 7:527-538

Okada K (2007) Plasma-enhanced chemical vapor deposition of nanocrystalline diamond. Sci Technol Adv Mater 8:624-634

Smetana AB, Wang JS, Boeckl JJ, Brown GJ, Wai CM (2007) Finetuning size of gold nanoparticles by cooling during reverse micelle synthesis. Langmuir 23(21):10429-10432

Smetana AB, Wang JS, Boeckl JJ, Brown GJ, Wai CM (2008) Deposition of ordered arrays of gold and platinum nanoparticles with an adjustable particle size and interparticle spacing using supercritical $\mathrm{CO}_{2}$. J Phys Chem C 112:2294-2297

South AB, Whitemire RE, Garcia AJ, Lyon LA (2009) Centrifugal deposition of microgels for the rapid assembly of nonfouling thin films. Appl Mater Interfaces 1(12):2747-2754

Stephen W, Clark J, Harbold M, Wise FW (2007) Resonant energy transfer in PbS quantum dots. J Phys Chem C 111:7302-7305

Tessler N, Medvedev V, Kazes M, Kan S, Banin U (2002) Efficient near-infrared polymer nanocrystal light-emitting diodes. Science 295:1506-1508

Ullrich B, Xiao XY, Brown GJ (2010) Photoluminescence of PbS quantum dots on semi-insulating GaAs. J Appl Phys 108:013525(1)-013525(5)

Ullrich B, Wang JS, Brown GJ (2011) Analysis of thermal band gap variations of $\mathrm{PbS}$ quantum dots by Fourier transform transmission and emission spectroscopy. Appl Phys Lett 99:081901(1) 081901(3)

Ullrich B, Wang JS, Xiao XY, Brown GJ (2012) Fourier spectroscopy on $\mathrm{PbS}$ quantum dots. Spectrosc Photonics Int Eng (SPIE) 8271:82710A(1)-82710A(6)

Wang JS, Smetana AB, Boeckl JJ, Brown GJ, Wai CM (2010) Depositing ordered arrays of metal sulfide nanoparticles in nanostructures using supercritical fluid carbon dioxide. Langmuir 26(2):1117-1123

Wang JS, Brown GJ, Hung WC, Wai CM (2012) Supercritical fluid deposition of uniform $\mathrm{PbS}$ nanoparticle films for energy-transfer studies. Chem Phys Chem 13(8):2068-2073

Ye XR, Wai CM, Zhang QD, Kranov Y, McIlroy DN, Lin YH, Engelhard M (2003) Immersion deposition of metal films on silicon and germanium substrates in supercritical carbon dioxide. Chem Mater 15:83-91

Zhang CY, Yeh HC, Kuroki MT, Wang TH (2005) Single-quantumdot-based DNA nanosensor. Nat Mater 4(11):826-831 